\title{
Pragmatic Function(s) of Pronouns and Pronominals in Nigerian Hip Hop Music
}

\author{
Michael Temitope Ajayi \& Ibukun Filani \\ *http://dx.doi.org/10.4314/ujah.v15i2.6
}

\section{Abstract}

Rivalry and enmity are phenomena that seem to have permeated the Nigerian music industry, especially the hip hop genre. In this regard, Nigerian hip hop artistes employ language to demonstrate their superiority over one another. A strategy employed by Nigerian hip hop artistes to assert their differences and superiority is the pragmatic use of pronouns. Here, pronouns are said to do more than achieve coherence.The paper investigates how Nigerian hiphop artistes use pronouns to achieve pragmatic meanings. Nigerian hip hop artistes employ pronouns to project their individuality and personality; identify and solidarise with their fans, and map boundary and polarity with their rivals. The paper submits that, while using pronouns, the Nigerian hip hop artistes express a sense of rivalry and enmity, individuality and personality; identity and solidarity.

Key Words: Rivalry, Nigerian Hip hop artistes, pronouns, pragmatic meanings

\section{Introduction}

The goal of pragmatic research is to investigate language use, most especially, the communication of meaning via linguistic expressions in relation to the language users. Pragmatics recognises that communication takes place chiefly through the means of language plus some extralinguistic 
factors, because language users are social beings who use language based on the premises of their soico-cultural orientations. Pragmatics, therefore, investigates meaning according to the users of language and meaning in the situationsin which language is used.In line with this, Thomas (1995) makes a distinction between two kinds of meanings: abstract meaning and contextual meaning. The abstract meaning refers to what a word, phrase or sentence could mean, and it is also known as dictionary meaning of words. Contextual meaning, which is also known as utterance meaning, refers to what a language user actually does mean by his/her expressions. It is got from the pairing of language and the situation of language use.

Apart from these, much of contemporary research works in pragmatics has been dedicated to the investigation of speakers' intention. The term force has been used to refer to what a speaker intends his/her utterance to mean. According to Thomas (1995), the forceof an utterance or a word refers to the communicative intentions of the speaker of the utterance or word. Both utterance meaning and force are types/levels of speakers' meaning, with the utterance meaning being the first level and force being the second level. We use example 1 below to illustrate the difference between the two levels of speakers meaning.

\section{Is This Your House?}

If 1 is said to someone in a context without ambiguity of reference, such that the demonstrative this indicates a unique entity (your house) and your refers to the hearer, the following interpretations will be made. At the utterance meaning level, the speaker may be seeking clarification as to where the hearer lives. However, the pragmatic force is different from the speaker's request for information. It may be that $\mathrm{s} / \mathrm{he}$ is mocking the hearer, rejecting the hearer's offer to give 
her/him a place to spend the night, or the speaker may be expressing admiration for the hearer's house. Force is derived from utterance meaning but utterance meaning may not be derived from force. The intended force of an utterance is suggested by the context and/or paralinguistic features (intonation, length, pitch, tone etc.) and non-linguistic features (gestures, physiognomy and bodily expression of emotions).

Our goal in this study is to investigate the pragmatic force of pronouns and pronominals in the language use or discourse of Nigerian hip-hop artistes' lyrics. We base the study on the premises that, Nigerian hip-hop artistes, just like other language users, have certain intentions that underline the selections of words in the lyrics of their songs, which may be or may not be stated in the lyrics of the songs and that the intentions that underline the use of an utterance or a word are recoverable whenever the utterance or word is examined in the context of its use.We have used the term context to subsume contextual beliefs as identified by Odebunmi (2006) to include knowledge of language, subject or topic of interactions, and previous or immediate socio-cultural and situational experiences. We have used the term discourse in the broad term to mean language use (Brown and Yule, 1983) or language choice of interactants.

It is no gainsaying that life is full of comptetion and competitors, hence, the commonplace rivalry that exists among individuals who have chosen to establish their prominence in the same walk of life. The scenario painted above aptly describes the trend of things in the Nigerian music industry, especially the hip hop section of the industry. Hip hop artistes in the Nigerian music scene have been seen to demonstrate the rivalry among them in their use of language, resorting to name-calling and abuse (Ajayi, 2012). Given this contextual background of events in the Nigerian hip hop scene, there is no doubt that the artists' language choice would 
be directed at enhancing the artists' senses of superiority. Therefore, to investigate their language choices, there is need to adopt approach that will take cognisance of the underlying background information of the events in the industry.

The data for this study weregathered from the lyrics of selected Nigerian hip-hop artistes. Extracts from songs were taken from lyrics of songs to illustrate the pragmatic force of the pronouns and pronominals that are used in the Nigerian hip-hop genre. To derive the extract, we purposively sampled songs which are printed in pamphletssold by newspaper vendors. To validate the contents of the lyrics pamplets, we equally listened to the songs from which extracs were taken. The Songs that appear in pamphlets are popular and sensational ones, they are the ones mostly played by radio DJs. We selectedthe songs based on prominent use of pronouns therein. In the next section of the paper, we present an overview of pronouns and hip-hop music, especially as contextualised in Nigeria.

\section{Pronouns: Definition, Types and Grammatical Functions}

Pronouns are commonly defined as words used in place of nouns.Leech (2006:95) defines pronouns as "a class of words which fills the position of nouns or noun phrases, and which substitutes for, or cross-refers to, other expressions." Huddleston and Pullum (2005:100) notes that pronouns are "distinguished syntactically from common nouns and proper nouns by their inability to take determiners." Grammatically, pronouns have case, number, gender and persons distinctions. They may perform adjectival or determiner functions in that they could be used to point out certain nouns. Also, in their grammatical functions, they could be used as subject and/or object of the verb, predicative complement, or complement of a preposition. 
Quirk and Greenbaum (1973) identify the following as pronoun types: personal, reflexive, possessive, relative, demonstrative and reciprocal. Personal pronouns (e.g. I, me, we, you, he, she, her, they etc.) are found in the subject or object position and they function as replacement for coreferential noun phrases in neighbouring clauses, while reflexive pronouns (e.g. myself, ourselves, yourself, herself, themselves etc.) replace a co-referential noun phrase within the same finite verb clause. Possessive pronouns are those that are used to show ownership. Possessive pronouns are divided into two classes: attributive (my, our, her, his, its and their) and nominal (mine, ours, yours, hers, his and theirs). The attributives are used like determiners while the nominal are used like the genitive with ellipsis. Relative pronouns (e.g. who, whose, which, whom, etc.) are similar to interrogative pronouns in form but are different from them in syntactic function. The relative pronouns are used for introducing a relative clause, while in the interrogative function; they are used as markers for interrogative utterances. Demonstrative pronouns (this, these, that and those) can function as determiners. The reciprocal pronouns are just two, each other and one another, and they express the idea of reciprocal relationship.

It is important to mention the concept of persons in pronouns which are three: first, second and third persons. The first person refers to the speaker,the second person denotes the hearer with or without other people, and it excludes the speaker. The third person denotes people, things and so on and it excludes both the speaker and the hearer (Leech, 2005). Regardless of the persons or types of pronouns, there is always an antecedent for pronouns in the context where they are used.Leech (2005) opines that pronouns are understood to be known in the context where they are used. The context, cotext and situational or background information, that surround 
a text become important in the recovery of the antecedent of the pronouns.

\section{Pronominals}

The term pronominal is sometimes used instead of pronouns, especially when pronouns are used as modifiers of nouns. This is why Leech (2005) describes pronominal as the adjectival term that relates to a pronoun. The class of possessive pronouns falls into this category. The words that fall into this category are syntactically adjectives, which are mostly used to modify nouns, but they behave like pronouns though they differ from pronouns in their functions. Two groups of pronominal can be identified: the pronominal possessive adjectives and pronominal possessive pronouns. Possessive pronouns functioning like adjectives are pronominal possessive adjectives while possessive pronouns functioning like pronouns are pronominal possessive pronouns. We use $2 \mathrm{a}$ and $b$ to illustrate the differences:

2a. Your teacher is a wonderful man (pronominal possessive adjective)

2b. Yours is a wonderful man (pronominal possessive pronoun)

The table below further exemplifies the differences:

Pronominal possessive adjectives Pronominal possessive pronouns

First person

Second person

Third person my/our (paper)

your (paper)

his/her/its/their (paper) (that paper is) mine/ours

(that paper is)yours

that paper is) his/her/its/theirs

This distinction is also applicable to the use of interrogative markers and demonstratives as shown in 3 and 4

3a. What newspaper do you read?

(possessive adjective)

3b. What do you read?

(possessive pronoun)

4a. Those girls are beautiful

(demonstrative adjective)

4b. Those are beautiful girls

(demonstrative pronouns) 


\section{Pronouns: Discourse Functions}

The notion of context in the use of pronouns draws up their discourse functions. One of the most important functions of pronouns in a text is to help the text achieve cohesion and coherence. It is on this note that Huddleston and Pullum (2005: 101) asserts that 'most pronouns are used either deictically or anaphorically'. Pronouns, therefore, help to set up and achieve internal networks of meaning in a text. As cohesive agents, pronouns help a text to achieve texture in that they have cohesive relationship with their antecedents. Their presence in a text presupposes the presence of a nominal entity in the text or in the situation where the text is produced (context). The cohesive relationship is set up since the interpretations of the pronouns are dependent on the identification of nominal elements in the discourse as well as the underlying semantic relation (Halliday and Hassan, 1976:2-4; Brown and Yule, 1983:191).

According to Halliday and Hassan (1976), cohesive relationships occur in a text when the interpretation of some elements in a text depends on other parts of the text. In other words, pronominal elements cannot be interpreted semantically without making reference to somewhere else (Ogunsiji, 2007). Brown and Yule (1983: 192-193) identifies two reference types in the interpretation of pronouns: exophoric and endophoric. When the interpretation of pronouns can be achieved within a text, they are said to have endophoric relations; when their interpretation is not textually overt but lies beyond the text, they are said to have exophoric relations (Ogunsiji, 2007).The endophoric reference is further divided into anaphoric and cataphoric. The anaphoric cohesive reference tie demands that the hearer looks back into the text for its interpretation, while the cataphoric cohesive reference tie demands that the hearer looks forward for its interpretation. Most especially, under the endophoric co-referencing, 
pronouns could be viewed as lexical replacement since they are used to replace nouns. Two conditions for their use are relatedness of reference and relatedness of meaning.

\section{Interpreting Pronominal Reference in Discourse}

In the use of pronouns, meaningfulness as well as cohesiveness is achieved when the pronouns are properly interpreted. Brown and Yule (1983) opines that the hearer uses the following in interpreting pronouns:

i. An antecedent- nominal expression

ii. And/or an antecedent- predicate expression

iii. And/or an implicit antecedent predicate

iv. And/or the roles of antecedent nominal expression

v. And/ or the new predicated attached to the pronoun.

In the initial four statements, pronouns are interpreted based on a given entity in a text since the pronoun's nominal entity must have been mentioned before the pronoun. However, the last condition caters for instances where a pronoun occurs in a text without a previous mention of the antecedent of the pronoun. In such instances, new information is attached to a given element- the pronoun, which provides the hearer with a new interpretive procedure.

\section{Pronouns: Sense and Reference}

Since our goal is to examine the implicit intentions of hip hop artistes for using pronouns in their music, it is important to examine the meaning possibilities of pronouns. To start with, pronouns are associated with some kind of mental representations of the things they can be used to replace.For instance, the use of it as against he may primarily denote that entity being replaced by the pronoun is inanimate while he would indicate that the entity is human and masculine. These representations constitute the sense of the 
pronouns and are closely linked to the grammatical form and functions of pronouns. We have used the term sense here, following Cruse (2000) who notes that the function of a word is to mobilize concepts which are the main constituents of sense and that sense constrains (if it does not completely determine) reference. By reference of pronouns, we mean both the linguistic and contextual meanings of pronouns. The linguistic meaning is predictable since it is the dictionary meaning while the contextual meaning is unpredictable since it is based on speakers' intention.

More particularly, the reference of pronouns helps to identify their referential functions. Here, the idea is not what a pronoun refers to in a text but what the producer of the text uses the pronoun to refer to; that is, the intention of the speaker/ writer. Whatever the form of a pronoun used, its referential function depends on the speaker's intention on the particular occasion of use. Pronouns could refer to given entity or new entity in interaction (Brown and Yule, 1983). In the first instance, the pronoun is a substitution for a noun that has been initially mentioned and in the second instance; a pronoun is used without an initial mention of the noun it replaces. In the second instance, the interpretation of the reference of these pronouns depends on what is predicated of them, and is not solely determined by the information in the preceding discourse' (1983:219). The sentence below illustrates this:

1. I teach English literature in Trinity College on parttimebasis.They don't have literature teacher and they do not want to employ me on full-time.

They does not replace the given information here'Trinity College', since it does not referentially and explicitly refer to it. The pronoun they indicates a nominal entity which 
has not been mentioned at all in the utterance. The speaker simply assumes that he can refer to the staff or the school board without explicitly mentioning them as a nominal entity in the sentence, since it can be inferred from the sentence that 'they' is definitely not replacing 'Trinity College' but the 'people (workers, students etc.) in Trinity College'. They, therefore, refers to implied entity.

With the use of pronouns, the speaker indicates that reference is immediately available to the hearer. It is then left for the hearer to determine the precise reference, by searching for a referent which would support a meaning yielding the right contextual effects. The hearer has to depend on his linguistic competence to uncover the type of pronouns used and their grammatical functions, and what Ogunsiji (2007) terms pragmatic predicate. Ogunsiji (2007:118) asserts that "the choice of a pronominal form is not made arbitrarily but it depends on sociolinguistic and discourse rules which are context sensitive and depict the level of sociolinguistic and discourse competence of the speaker(s)". To us, pragmatic predicate entails the socio-cultural knowledge as well as other non-linguistic knowledge that are brought to play in interactions. Both pragmatic predicate and linguistic competence are accentuated as contextual beliefs in Odebunmi (2006). These contextual beliefs are held prior to or during the process of an interaction and they facilitate the communicative process. They include the knowledge of the topic of interaction, knowledge of word choices, referents and references and socio-cultural experience.

The pronoun they illustrates how pragmatic predicate influences the interpretation of pronouns. Theyis primarily the plural form of the third person subject pronoun. However, in Nigerian English, due to the socio-cultural influence- the belief that elders should be respected, they is used in the 
honorific sense and not the plural sense (among young learners and speakers of the language).

2. Teacher: Why did your father fail to come as requested by the principal?

Student: They said that they will come tomorrow morning.

Here, the use of they rather then he, is not due to lack of linguistic competence. The use reflects the socio-cultural belief of the student that he must respect his father. Given that the teacher too is aware of this socio-cultural knowledge, he would interpret they to mean the father of the student.

\section{Hip Hop Music: its Origin, Definition and Nature}

Hip Hop as a genre of music emerged in the mid 1970s in South Bronx and the northeast (New York). As a genre of music, it has its culture, which reflects in the dressing style, language use and life style of many youths across the globe. This brand of music emerged when DJs in New York started isolating the percussion break from funk or rock songs so that the audience could dance to it. In the opinion of Shani (2004), attempts to define hip hop have been a challenging task. His position is obviously predicated on the fact that scholars vary in their opinions and conception of the concept. For instance, Boyd (2003) views hip hop asa testament to the strength of the oppressed and it has continued to become a vital tool often used to conquer or overcome the obstacles that American life often imposes on inner-city urban communities, most especially the youth. Westbrook (2002:64), on the other hand, in his Hip Hoptionary (the Didctionary of Hip Hop Terminology), defines hip hop as:

The artistic response to oppression. A way of expression in dance, music, word/song. A culture that thrives on creativity and nostalgia. As a 
musical art form, it is stories of inercity life, often with a message spoken over beats of music. The culture includes rap and any other venture spawned from the hip hop style and culture

Obvious in the excerpt above is the fact that hip hop comes as a means through which artistes let out their feelings to oppression. Perhaps, it could be argued that Westbrook's position is in line with that of Rose (1994) who asserts that :

Hip hop is a cultural form that attempts to negotiate the experiences of marginalisation, brutally truncated opportunity, and oppression within the cultural imperatives of African American and Caribbean history, identity, and community. It is the tension between the cultural fracture produced by post-indusrial oppression and the binding ties of black cultural expressivity that stes the critical frame for the development of hip hop (cf Ajayi, 2012 : 4).

Rose emphasizes the fact that hip hop evolved following attempts to reveal the oppressive experiences of the youths in the multicultural milieu of the New York boroughs. The youths in New York were oppressed, repressed and segregated due to the post-industrial economic backlask, rapidly changing political landscapes, and shifts from segregation to multicultural integration and back to cultural polarisation (Rose, 1994).

Hip hopmusic, equally known as rap, consists of a rhythmic style - rap usually accompanied with backing beats. Rapping or MC-ing is the term often deployed to refer to artistes who demonstrate superior lyrical ability and singing prowess. However, recently, the term has been used, demeaningly, to refer to artistes with less focus on lyrical 
talent and ability, the category to which many of the contemporary artistes have been categorised. This brand of music has however gained more popularity all over the world, Nigeria inclusive.

Some factors have been identified as being responsible for the unprecendented rise of hip hop, particularly in the $U \mathrm{~S}$ in the 1970s. Among these factors are the fact that producing hip hop was not capital intensive. The MC could create and combine "meaningless" rhymes or lyrics, at times, by poking fun at friends and enemies with less attention on quality. Also, the skill or prowess required to produce hip hop could be informally learned or acquired by mere observing and mimicking a musician rather than being tutored in music lessons or schools. Similarly, the decline of disco, funk and rock music in the mid and late 70 s could be said to be part of the factors that led to the rise of hip hop during this era. Disco was very popular among the blacks, especially males in American clubs and some parts of Europe. These lovers of disco in the US rejected it in embrace of the raving hip hop at the time. Hip hop then rose to take the advantage of the strong and danceable beats of disco to provide a musical outlet for the masses that had now abhorred disco (Ajayi, 2012).

Beside these aforementioned factors that are said to contribute to the rise of hip hop in the 70s, some sociopolitical events could also play an important role. The CrossBronx Expressway was constructed in 1959; a development that led to the displacement of many middle class white communities. Consequently, there emerged a widespread of unemployment among the remaining blacks, as many stores and factories had fled the area. The erection of the Co-op City 15,000 apartment at the nothern edge of the Bronx in 1968 sent the last of the middle class from the area, and the black and Latino gangs began to grow in power. 
By 1979, the first hip hop recording was done by a Sugar Hill Gang, a New Jersey based singer, and by 1980, all the vital and major elements and techniques of hip hop were already in place. This was a period during which hip hop became very popular among African- Americans, even beyond the shores of New York. This era was reputed as the golden age or era in the history of hip hop. Artistes that featured prominently during this era included Rakim (from the hip hop duo of Eric B and Rakim), Big Daddy Kane (of the Juice Crew), Kool G Rap, Masta Ace, Ice Cube, LL Cool J, and a host of others. Although the actual period hip hop music surfaced in Nigeria could not be stated with precision, it might not be out of place to posit that the first set of hip hop artistes in Nigeria include the likes of Idris Abdulkareem, Tony Tetula, who formed the Plantashun Boyz group in the early period of the year 2000. Since this period, what has been observed as a phenomenon that has characterised this industry in Nigeria is superiority tussle that has birthed rivalry among artistes.

\section{Hip Hop in Nigeria}

The period between the late 1990s and the early 2000 marked the birth of hip hop music in Nigeria, with artistes like Idris Abdukareem, Tony Tetula, among others championing the cause. It is a genre of music in the country that features a mixture of the American and Nigerian indigenous cultures. This mixture of the African American and Nigerian cultures is perhaps what has made this genre of music have immeasurable influence on many youths in the country.

It is worthy of note that, Hip hop, as a genre of music in Nigeria has enjoyed much scholarly attention. For instance, Omoniyi (2005), examining the linguistic situation in Nigerian hip hop music domain, submits that code switching is a common feature of Nigerian hip hop. He believes code 
switching with indigenous languages in Nigeria is a means of resisting the infiltration of and dumping of American hip hop music culture in Nigeria. In other words, although Nigerian hip hop artistes would want to follow the pattern of performance of their American counterparts, they want to assert their identity through their use of the mixture of their local languages and English. In fact, corroborating this view, Adegoke (2011) argues that code switching in Nigerian hip hop music is not only an attempt to restrict the influx of African American hip hop culture or cultural hegemony, but also to create a mark of style and creativity. Perhaps this is further made possible by the fact that many of the Nigerian hip hop artistes do not demonstrate high level of proficiency in the English language such that they could conveniently and comfortably operate with the language without any recourse to their local languages.

Omoniyi et al (2009) also looks at the linguistic and other features of Nigerian hip hop such as rhyme, blend of local languages, light reference to sex and absence of gangsterism. While one may want to agree with the position of these scholars on the presence of rhyme and mixture of local languages in the Nigerian hip hop music, the assertion that Nigerian hip hop artistes make light reference to sex is somewhat questionable. In fact, Ajayi (2012) refers to this assertion as overgeneralisation. This is because heavy reference to sex, though sometimes through conceptual metaphor, is a major feature of many Nigerian hip hop songs.

Still talking on the linguistic feature of Nigerian hip hop music, Liadi and Omobowale (2011) opine code alternation by Nigerian hip hop artistes in their songs is a major phenomenon responsible for the increasing consumption and wide acceptance of the music among Nigerian youths. Omoyele (2011) equally submits that the use of Nigerian Pidgin English and Nigerian indigenous languages 
by Nigerian hip hop musicians is purposely to construct national and linguistic identity among Nigerian youths. These artistes, according to him, are taking a cue from FelaAnikulapo-Kuti, a pathfinder on the use of Nigerian Pidgin and the indigenous languages.

Ajayi (2012) studies the abusive language used by some Nigerian hip hop artistes with a view to identifying the Face-threatening Acts used by these artistes to damage each other's positive and negative faces. What could be deduced from the work of this scholar is the fact that rivalry and selfaggrandisement are common phenomena among Nigerian hip hop artistes, hence the much atmosphere of 'conflict' that permeates the Nigerian hip hop music industry.

\section{8. $\quad$ Findings}

\subsection{Pronouns/Pronominals, Individuality, and Self- assertion}

Pronouns and pronominals are linguistic expressions that could be used to assert individuality or personality and self. Here, these pronouns and pronominals are used by the artistes to foreground, and bring to the listeners' awareness their individuality and personality, since the pronouns draw attention to what the artiste says he possesses, his achievements, that mark out of his contemporaries. Likewise, pronominals are used to modify nominal entity and thereby making reference to the nouns that are related to them. Specifically, we found the first person singular pronouns and the first person pronominal possessive adjectives performing this function in the lyrics of hip-hop songs. The first person typically point to the speaker or writer, and as an actor, s/he becomes the performer or recipient of the action in the sentence. The first person pronominal possessive adjectives inasmuch as they indicate ownership; pragmatically, they 
indicate exclusiveness. Instances of these pronouns and their usage are given below:

Text one: $\quad$ Shebi emi nashani (it is I)

$\underline{I}$ want you to be $\underline{\boldsymbol{m} \boldsymbol{y}}$ honey

$\underline{\boldsymbol{I}}$ want you to be $\underline{\boldsymbol{m} \boldsymbol{y}}$ lady

Dance to the beat, no dey slack $\underline{\boldsymbol{m} \boldsymbol{y}}$ baby (do not delay my baby)

(Whizkid,2011in “Naija Blast,”2011)

Text two: when you see $\underline{\boldsymbol{m} \boldsymbol{e}}$ come around

$\underline{I}$ got you looking at $\underline{\boldsymbol{m} e}$

$\underline{I}$ don't need to spend $\underline{\boldsymbol{m} y}$ cash

Cos $\underline{m y}$ swag $^{1}$ is not hard to see (because my dexterity is not in doubt)

intact)

Cos $\underline{\boldsymbol{m} y}$ swag don't lie (because my dexterity is

(Whizkid, 2010in “Naija Blast,’2011)

Text three: $\quad \underline{I}$ really really like it

Forever, forever

$\underline{I}$ really really like it

Oh baby

$\underline{\boldsymbol{I}}$ wish $\underline{\boldsymbol{I}}$ was your man

Maybe anytime you are lonely

Can $\underline{I}$ be the one you are calling

$\underline{I}$ hope you understand

Please take $\underline{\boldsymbol{m} \boldsymbol{y}}$ hand and go with me $\underline{\boldsymbol{m} \boldsymbol{y}}$ love

(Forever : P-square in "Naija Blast," 2011)

In the excerpts above, the artistes make extensive use of the first person personal pronouns I, emi(I),me and the possessive

${ }^{1}$ Slangish term used common Nigerian youths to refer to their exuberance 
$m y$. These pronouns, apart from deictically pointing at their referents, they also indicate the individuality of the referents. The pronominal adjective, $\boldsymbol{m y}$, indicates a restricted sense of the nominal entity coming after it. The artistes in the texts above use this pronoun to note that the hand, love, honey, cash or baby strictly belong to them and no other person. The artistes use the first person singular pronouns to emphasize their personalities and individuality.

\subsection{Pronouns/Pronominals, Solidarity and Collectivity} Ogunsiji (2007:118) asserts that pronouns are strategically used to express solidarity and collectivity. It is in view of this that linguists identify the exclusive 'we' and the inclusive 'we'. The exclusive 'we' is made up of the speaker plus other(s), excluding the addressee while the inclusive 'we' is made up of the speaker and the addressee(Yule 1996:11). In solidarising and indicating collectivity, speakers make use of either the exclusive we or the inclusive we, and the pronominal counterpart, ours and theirs.

In the hip-hop songs under investigation, we found the use of both the exclusive "we" and inclusive "we". In the first instance, an artiste uses the exclusive "we" to solidarise himself with other artistes or actors, probably his producers or directors in the music business. In the second instance, the artiste uses the inclusive "we" to solidarise himself with not just other actors in the music business but his fans and listeners. We illustrate this below:

Text four: This na the unexpected collabo (this is the unexpected collaboration)

Ruggedman and Eedris Abdulkareem

What we done no one can stop it

Clubs $\underline{\boldsymbol{w} \boldsymbol{e}}$ rock rock it 
$\underline{\text { We }}$ drop shit ${ }^{2}$, but none can flush it

Text five: $\quad \boldsymbol{W} \boldsymbol{e}$ remember independence

When our freedom we received

And the call to fight for unity

And the vision we believed

Fifty years have gone by quickly

Years of laughter, joy and pain

But our future is united

And faith and hope remain

So we sing together...

We rise when we fall

$\boldsymbol{W} \boldsymbol{e}$ 're still standing tall

We make it through the night

We are still fighting together...

(Abdulkareem, 2008).

In Text four, the use of 'we' is meant to indicate collectivity between the two artistes that performed the song- Ruggedman and Eedris Abdulkarim; and in addition, indicates solidarity between the two of them. The song begins with the line This na the unexpected collabo, to show that the two of them were not expected to sing together, perhaps owing the rivalry between them. They use the first line to indicate that even though they were not expected to perform together, the two of them have buried the hachet and have come together to show what they are capable of doing(collectively). The pronoun we in the lyrics excludes the listeners as well as the fans of these two artistes, but includes the two artistes, as evident in the propositional contents of the lines of the song.

On the other hand, the inclusive we is found in Textfive. In the text, the artiste focuses onhimself, his fans

${ }^{2}$ Nigerian Pidgin word for faeces 
and any other listeners who are from the artiste's country of origin- Nigeria. The artiste made reference to Nigeria's struggles for independence and the independence celebrations of the year the song was released. The use of we here, is therefore, inclusive since it includes the artistes (the speakers), the addressee (Nigerians), the fans of the artistes and whoever comes across the song by chance. Also, the artist use of the pronominal our pragmatically indicate that the modified noun is collectively owned by the artistes and their fans and the addressees

\subsection{Pronouns, Identity, Polarity and Boundary Mapping \\ Ogunsiji (2007:119) asserts that as language users} solidarise through language, 'they also use language to segregate, to polarise, and to map boundaries'. In solidarity, collectivity, polarity and boundary mapping, a sense of identity is necessarily embedded because people solidarise, polarise, and map boundaries on the basis of construed identity.' What is being implied here is that in as much as pronouns can be used to indicate collectiveness, they can also be used to indicate differences. Basically, under this notion, pronouns are used to map out differences in social groups or categories. We illustrate this with the following extracts from one of the songs selected for this work:

Text six: $\quad$ See them, see them

They wanna beef me

Now that they see BET on my CV

Now that $I$ be frequently on the TV

They wanna go there but still can't afford the TP

My motto is do more talk less

Never get mad at another man's success...

No sir, they can't mess with my flow sir 
Some of them said they are better than me...

Can't they tell $I$ am the boss

Some of them wanna blow

Sir maybe they should come and pay me tolls

(Beef: MI in “Naija Blast,”2011)

In the song from which Text six is taken, the artiste, $M I$, attacks other artistes whom he perceived as his enemies in the Nigerian music scene. In the extract, $M I$ notes that since he has been able to achieve the feat of having his music played on BET- Black Entertainment Television, his enemies and "haters" who are also music artistes and who have not been able to have their music on an international channel such as BET, have become envious of his feat. From the use of pronouns in the song, we will see a repeated use of the first person singular pronouns $I, m e$ and $m y$, which are used to indicate the artiste's individuality. In opposite to the first pronouns, MI uses the third person pronouns they, them to referto his "haters" and enemies. Although, haters and enemies are not mentioned in the song, the referent of the third person pronouns can be taken as those who oppose the artiste if the propositional content of the song is taken into consideration. The lines, No sir they can't mess with my flow, some of them said they are better than me, show that MI uses the song to lambaste other artistes that, perhaps, have voiced their hatred for $M I$.

The first person pronouns are thus used against the third person pronouns to indicate the meaning:

MI versus other artistes (his opponents, haters and enemies) 
$\begin{array}{lll}\text { Me } & \text { versus } & \text { them } \\ \text { MI's songs } & \text { versus } & \text { their songs }\end{array}$

Text 7:

$O$ ní tìre, mo ni temi (You have yours, I have mine)

But temi lowa fe ronju mo (But you are so carried away by mine)

You wan thief my kele (You want to steal my girlfriend)

You wan you wan thief my kele (You want to steal my girlfriend)

Kele ( thief my kele)

You get your own (You have yours)

$\boldsymbol{I}$ get $\boldsymbol{m} \boldsymbol{y}$ own (I have mine)

But na my own wey dey (But mine is what gives you pleasure the most)

Sweet you pass

( Thief my Kele: Banky W featuring Oladele in "Naija Blast,'2011)

In this excerpt, Banky $\mathrm{W}$ uses the first person personal pronouns and possessive pronouns to map boundaries with his rival(s) whom he claims is/are covetous. Here, $O$ "you" is used against mo "I", tire "yours" against temi "mine". This is made explicit below

$\begin{array}{lll}\mathrm{O}(\text { You }) \quad \text { versus } & \text { Mo }(\mathrm{I}) \\ \text { Tire (Yours) versus } & \text { Temi (Mine) }\end{array}$

Micheal Temitope Ajayi is of Department of Linguistics and African Languages

While Ibukun Filani is of Department of English, Both are of University of Ibadan, Nigeria michealtemitope@yahoo.com phylani@yahoo.com 


\section{Conclusion}

As mentioned at the beginning of this paper, superiority tussle has been a major cause of the rivalry that exists among Nigerian hip hop artistes. In the paper, we have been able to point out that Nigerian hip hop artistes employ the use of pronouns such as I, and pronominals such as MY, MINE to assert their individuality, the pronoun WE and pronominal OUR to show collectivity and solidarity, and pronouns such as YOU, THEY, THEM, THEIRS and the pronominal YOURS to map boundary with their rivals. What is deduceable from this therefore, is the fact that, more often than not, the use of second and third persons, especially third person personal pronouns connote rivalry and enmity in the Nigeria music industry. Also, we have been able to further reinforce the fact pronouns, apart from helping to achieve coherence in discourse, perform pragmatic functions in line with the position of Ogunsiji (2007). 


\section{References}

Abdulkareem, E. (2008)The king is back [CD]. Lagos, Nigeria:

Adegoke, A. (2011). Language and identity representation in popular music.International

Journal of Innovative InterdisciplinaryResearch, Issue 1, Dec. 2011 pp 150-164

Ajayi, D. O. (2012). The Language of abuse in the Nigerian hip hop music. An unpublished

M.A project, Department of English, University of Ibadan, Nigeria.

Boyd, T. (2003). The new $H N I C$ : the death of civil rights and the reign of hip hop. New York: New York University Press.

Huddlestone, R.andPullum, G. K. (2005).A student's introduction to English grammar. Cambridge : Cambridge University Press

Gillian, B. and George,Y. (1983).Discourse Analysis. Cambridge: Cambridge University Press

Leech , G. (2006). A glossary of English grammar. Edinburgh: Edinburg University Press

Liadi, O.F. and Omobowale, A.O. 2011. Music, multilingualism and hip hop consumption among youths in Nigeria. International Journal of Sociology and Anthropology, vol 3(12) pp 469- 477

Naijablast: my music [pamphlet]. (2011). Lagos, Nigeria:

Ochado Platinum

Omoniyi, T., Scheldb, S. and Oni, D. (2009). Negotiating youth identity in a transnational context in Nigeria.

Social Dynamics, Vol. 35, 1, pp.1-18.

Omoniyi, T. (2005). Hip-hop through the world Englishes lens: a response to globalisation. 
In Kachru, V. and Lee, J.S. (Eds) World Englishes and global popular cultures: Oxford: Blackwell. 195208

Omoyele, R. 2011. (M)other tongue, popular music and being retrieval. A paper presented at Codestria Conference, Morocco. pp 1-22

Omoyele, R. (2011). (M)other tongue, popular music and being retrieval. Codestria, Africa and the challenges of the twenty first century

Odebunmi, A. (2006). Meaning in English: an introduction. Ogbomosho: Critical Sphere.

Ogunsiji, A. (2007). Pronominal reference as discourse strategy in Soyinka'sAke, Isara and

Ibadan Ibadan Journal of English Studies, Volumes 4 and 5pp.115-125

Rose, T. (1994). Black noise: rap music and black culture in contemporary America.

Middletown, CT: Wesleyan University Press Shani, A.S. (2004). Unmasking hip hop: landscaping the shifts and impacts of a musical

movement. Diss. Communication, Culture and Technology. Arts and Sciences.

Georgetown University, Washington, DC.

Thomas, J. (1995). Meaning in interaction: an introduction to pragmatics. Essex: Longman

Westbrook, A. (2002). Hip hoptionary: the dictionary of of hip hop terminology. New York, NY:

Broadway Books Yule, G. (1996). Pragmatics. Oxford: Oxford University Press 